Original Article

\title{
PRESCRIPTION ANALYSIS OF HYPERTENSIVE PATIENTS AND AWARENESS AMONG PHYSICIAN REGARDING ANTIHYPERTENSIVE DRUG
}

\author{
PATIL P. J., PATIL V. S., BHORE P. \\ Marathwada Mitra Mandal's College of Pharmacy, Thergaon, Pune 411033 \\ Email: respjpatil@gmail.com
}

Received: 20 Nov 2019, Revised and Accepted: 19 Jan 2020

\begin{abstract}
Objective: This study was conducted to analyze prescriptions of the hypertensive patient and to determine the awareness of physicians regarding antihypertensive drugs.
\end{abstract}

Methods: Prepare a questionnaire by the pilot study on five physicians. Review and finalized the questionnaire after discussion with pharmacologist. The answers were seek for awareness. Moreover the prescription of 30 patients was collected from the same physician who has undertaken the awareness regarding Antihypertensive Drugs. Study was conducted during Oct-2019 to Dec 2019.

Results: Average 83\% awareness was found in the physician regarding antihypertensive drugs. Lack of awareness regarding diabetes and in ulcer patients was observed. Highest drug is given i.e. $\beta$ blockers in antihypertensive patients. To determine the irrationality in the prescription of hypertensive patients.

Conclusion: To determine the FDC's given to hypertensive patients. To determine the type of antihypertensive drugs given to patients.

Keywords: Rational use of Drugs, Survey on antihypertensive use, Awareness, Knowledge regarding combination drug use hypertensive patient

(C) 2020 The Authors. Published by Innovare Academic Sciences Pvt Ltd. This is an open access article under the CC BY license (http://creativecommons.org/licenses/by/4.0/) DOI: http://dx.doi.org/10.22159/ijcpr.2020v12i2.27521. Journal homepage: https://innovareacademics.in/journals/index.php/ijcpr

\section{INTRODUCTION}

Hypertension is a cardiac chronic medical condition result in increasing systemic arterial blood pressure. Hypertension means blood pressure is more than $140 / 90 \mathrm{~mm}$ of $\mathrm{Hg}$ [1]. Symptoms: headache, sleepiness, coma, confusion. If any person suffer from high blood pressure, but certain factors can seriously aggravate hypertension and increase the risk of complications [2]. Such as a tendency in the family to suffer hypertension, obesity, smoking, diabetes type 1 or type 2, kidney diseases, excessive salt intake, lack of exercise, certain medicines, such as steroids [3]. Antihypertensive agents are classified into Angiotensin-II receptor antagonists, $\beta$ blockers, $\alpha$-blockers, Calcium-channel blockers and Diuretics. Drug Interaction of Antihypertensive Drugs: 1. ACE inhibitors: a. ACE inhibitor+Alpha blocker: Acute hypotension, dizziness, fatigue or sweating develop, and to remain lying down until symptoms abate. $b$. ACE inhibitor+Clonidine: ACE inhibitors may potentiate the antihypertensive effects of clonidine, and this can be clinically useful. 2. Beta-blockers: Examples are Cardio selective $\beta 1$ blocker (Atenolol)+Antacid: Reduced cardioselective $\beta 1$ blocker absorption b. Cardio selective $\beta 1$ blocker (Atenolol)+antiarrhythmic: Increased cardiac adverse effect. Alpha-blocker: a. Alpha blocker+ACE inhibitor: 3. Calcium channel blocker: a. Bepridil+Quinolones: Increased risk of cardiac arrhythmias 4. Diuretics: If possible avoid beta-blockers especially in the presence of marked LVF (left ventricular failure) [4]. $\beta$ blockers that block $\beta 2$ receptors and cause shortness of breath in asthmatics. As with other drugs that may use for treating high blood pressure, sexual dysfunction may be observed in patients. $\beta$ blockers influence blood glucose level and mask the symptoms of hypoglycemia in patients with diabete [5]. Hypertension is associated with increased risk of stroke, myocardial infarction, atrial fibrillation, heart failure, peripheral vascular disease, and renal disease. Regarding changes in diet, a low sodium diet is beneficial for the patient with hypertension. The level hypertension can be treated on a number of features including a current blood pressure of patients, sodium or potassium balance, detection and omission of environmental toxic substances, changes in end or target organs for treatment, major factors for heart diseases and the age at diagnosis of prehypertension or at major risk for hypertension. Nowadays, lifestyle changes are also an important factor to lower blood pressure, before the initiation of prescription drug therapy [6]. In Antihypertensive the goal of treatment is to reduce blood pressure so that you have a lower risk of complications. Classification of Antihypertensive and their mechanism of action: 1 . Diuretics-Sympatholytic (Sympathetic Depressants) 1) BetaAdrenergic Blockers (Beta Blockers): Atenolol (Tenormin), Metoprolol (Lopressor) Beta-1 cardioselective Nadolol (Corgard), Propranolol (Inderal)-Nonselective Beta-1, Beta2 2) Centrally Acting Sympatholytics Agents or Adrenergic Blockers: Clonidine Hydrochloride, Methyldopa 3) Alpha-Adrenergic Blockers: Prazosin HCL 4) Adrenergic Neuron Blockers (Peripherally acting sympatholytics): Reserpine (Serpasil) and guanethidine (Ismelin) 5) Alpha-1 and Beta-1 Adrenergic blockers: Carteolol (Cartrol), Labetalol (Trandate). Direct-Acting Arteriolar Vasodilators-potent: Hydralazine (Apresoline)-Angiotensin Antagonists-Angiotensin-Converting Enzyme Inhibitors (ACE inhibitors) Captopril (Capoten), Enalapril (Vasotec), Lisinopril (Zestril) Angiotensin II receptor Antagonists (Blockers)-A-II Blockers: Losartan (Cozaar) Calcium Channel Blockers: Verapamil (Calan), Nifedipine (Procardia), Diltiazem (Cardizem [7].

Alpha blockers+Beta blockers: The risk of first-dose hypotension with prazosin (resulting in dizziness or even fainting) is higher if the patient is already taking a beta-blocker. This is likely to be true of other alphablockers, particularly alfuzosin, bunazosin and terazosin. In a small study, tamsulosin did not have any clinically relevant effects on blood pressure that was already well controlled by atenolol. Alpha-blockers and beta-blockers may be combined for an additional lowering of blood pressure in patients with hypertension. It is recommended that those already taking beta-blockers should have the dose reduced to a maintenance dose and begin with a low-dose of an alpha-blocker, with the first dose taken just before going to bed. They should also be warned about the possibility of postural hypotension and how to manage it (i.e. lay down, raise the legs, and get up slowly when recovered). Similarly, when adding a beta ${ }^{8}$. Adrenergic neuron blocker: Amfetamines+Guanethidine: When hypertensive patients taking guanethidine were given single doses of dexamfetamine or metamfetamine, the hypotensive effects of the guanethidine were completely abolished, and in some instances, the blood pressures rose higher than before treatment with the guanethidine. Direct acting 
arteriolar vasodilators Hydralazine $+\beta$ blockers: Plasma levels of propranolol and other extensively metabolized beta-blockers (metoprolol, oxprenolol) are increased by hydralazine, but an increase in adverse effects does not seem to have been reported [8-10].

Beta blockers: Beta-blockers were first developed by Sir James black at the imperial chemical industries in the United Kingdom in 1962. They are considered one of the most important contributions to clinical medicine and pharmacology in the 20th century, and Sir James black was awarded the Nobel Prize in 1988 for advances in medicine. Beta-blockers are one of the 4 oral medications proven in randomized control trials to decrease cardiovascular morbidity and mortality. The other three agents being AcE-inhibitors, antiplatelet and statins. This quadruple therapy reduces 6 mo mortality by $90 \%$ in AcS compared with treatment by none of these. The approximate life-saving potential of these agents has been estimated; betablockers 33\%, Aspirin 23\%, ACE inhibitors 20\% and Statins 15\%. clinical Pharmacology Although more than 100 beta-blockers have been developed, only about 30 are available for clinical use. Watersoluble beta-blockers (Atenolol, Nadolol) tend to have longer halflives and are eliminated via the kidney. Lipid-soluble beta-blockers (metoprolol, propranolol) are metabolized mainly in the liver and have shorter half-lives. Most of the drugs in the class are well absorbed after oral administration. The biologic half-life of betablockers exceeds the plasma half-life considerably. (e. g. propranolol, dosage twice a day despite a plasma half-life of $3 \mathrm{~h}$ ) [11-14].

\section{MATERIALS AND METHODS}

Literature survey is carried out to gather the drug-drug interaction information of $\beta$ blockers. First of all, to collect prescription of antihypertensive patients we went to the cardiologist. We collected 30 prescriptions of hypertensive patients from Physicians and from their hypertensive patients. All prescriptions were studied for their symptoms, diagnosis, and therapy and drug-drug interactions. The statistical analysis is done by the percentage comparison method. To carry out the survey on drug-drug interaction of $\beta$-blockers, the questionnaires were prepared under the guidance of pharmacologist. These questionnaires were presented to all cardiologists and answers given by them are noted. To carry out this survey we went to cardiologist. By taking the appointment of each physician questionnaires were presented to them. All these answers are viewed carefully and percentage calculation is done for each answer. Also we ask the physicians for, what type of drug-drug interactions are observed by them while prescribing the $\beta$-blockers? And what is the solution for this problem. Then we discuss about the methods which are carried out by physicians to avoid drug-drug interactions of $\beta$-blockers.

\section{Questionnaires}

DDI's Knowledge Survey among Physicians

Q.1. How much time taken by the $\beta$-blocker to normalize hypertension of Patients?

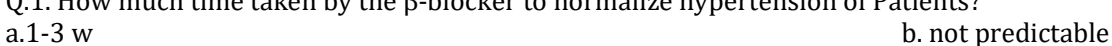

Q.2 Is $\beta 1$ selective blocker (Atenolol) is safer drug for asthmatic patient?

a. Yes

Q.3 Is $\beta 1$ selective blocker (Atenolol) is safer drug for a diabetic patient?

a. Yes

b. No

Q.4 If $\beta 1$ selective blockers are more useful than non-selective $\beta$ Blocker?

a. Yes

b. No

Q.5 If you preferred to prescribe antacids with $\beta$ blockers?

a. Yes

b. No

Q.6. Whether $\beta 1$ selective blocker used in younger patients or old age Patients?

a. Young age patient

Q.7. If Atenolol safer in pregnancy?

a. Yes

b. Old age patient

Q.8. If you are not prescribing $\beta 1$ selective blocker to old age patients then what would you like to prescribe them?

a. Diuretics, $\alpha$ blockers

Q.9 Along with $\beta$ blocker what combination of the drug usually prescribed?

a. Beta blockers+Diuretics

CCB's, ACE inhibitors

Ideal answers

Ans.1: 1-3 w.

Ans.2: Yes. Because it is $\beta 1$ selective blocker doesn't have any action on $\beta 2$ receptors and hence doesn't do bronchoconstriction.

Ans.3: Yes. Because it does not interfere with carbohydrate metabolism hence does not interfere with glycolysis hence safe to give in a diabetic patient.

Ans.4: Yes. Because it pass the blood-brain barrier and doesn't have an unfavorable effect on lipid profile (LDL/HDL) hence does not leads to reduce work capacity, fatigue loss of libido and nightmare and also reduces chances of bronchoconstriction.

Ans.5: Yes. Because usually hypertensive patients suffer from acidity problem and if there is a decrease in absorption of atenolol due to drug-drug interaction, then it is adjusted by prolong medication of $\beta$-blockers

Ans.6: Young age patients. Preferably for young non-obese who having hypertension due to stress and those with a post-ischemic attack.

Ans.7: Yes. But in the selective case where no other choice. If non-selective $\beta$ blocker is used in pregnancy then it can cause low birth weight,

decreases placental size, neonatal bradycardia and hypoglycemia.

Ans.8: Usually, for old age patient CCB's and ACE Inhibitors are used.

Ans.9: $\beta$ blocker+diuretics are usually used.

Table 1: Percentage patient in the age group

\begin{tabular}{lll}
\hline Age & Number of patients & Percentage \\
\hline Upto $30 \mathrm{Y}$ & 4 & $13.33 \%$ \\
$31-50 \mathrm{Y}$ & 22 & $73.33 \%$ \\
Above $50 \mathrm{Y}$ & 4 & $13.33 \%$ \\
\hline
\end{tabular}

Table 2: Male-female percentage ratio

\begin{tabular}{lll}
\hline Patients & Number of patients & Percentage \\
\hline MALE & 12 & $40 \%$ \\
FEMALE & 18 & $60 \%$ \\
TOTAL & 30 & \\
\hline
\end{tabular}


Table 3: Drug interaction with $\beta$-blockers

\begin{tabular}{|c|c|c|c|}
\hline Combination & Effect produced & No. of prescription & Percentage \\
\hline Atenolol+Antacid & Antihypertensive effect of $\beta$ blocker get reduced & 5 & $16.66 \%$ \\
\hline Atenolol+Diuretics & Dose of $\beta$ blocker drug gets reduced & 6 & $20 \%$ \\
\hline Total & & 11 & $36.66 \%$ \\
\hline Patients & Number of patient & Percentage & \\
\hline Male & 12 & $40 \%$ & \\
\hline Female & 18 & $60 \%$ & \\
\hline Total & 30 & & \\
\hline
\end{tabular}

Table 4: Percentage of drug therapy given to the patient's drug-

\begin{tabular}{|c|c|c|c|}
\hline Drug & Active pharmaceutical ingredients (API) & Number of patient prescribed & Percentage \\
\hline $\begin{array}{l}\text { Aten-25 } \\
\text { Atenol } \\
\text { Atenol (25) }\end{array}$ & $\beta$-Blockers & 5 & $16.67 \%$ \\
\hline $\begin{array}{l}\text { Amlopress } \\
\text { Amlovas (5) }\end{array}$ & Angiotensin-I Receptor Antagonist & 3 & $10 \%$ \\
\hline Temsan (40) & Angiotensin-I Receptor Blockers & 1 & $3.33 \%$ \\
\hline $\begin{array}{l}\text { Amlopress-At } \\
\text { Amlopin-At }\end{array}$ & Ace Inhibitors & 3 & $10 \%$ \\
\hline Losar Beta & Angiotensin-II Antagonist $+\beta$-Blockers & 5 & $16.67 \%$ \\
\hline $\begin{array}{l}\text { Amlopress-At } \\
\text { Amlopin-At } \\
\text { Stamlo Beta }\end{array}$ & B-Blockers+Ace Inhibitors & 7 & $23.33 \%$ \\
\hline Repalol-H & $\begin{array}{l}\text { B-Blockers+Angiotensin-II Antagonist+Diuretics } \\
\text { Total }\end{array}$ & $\begin{array}{l}6 \\
30\end{array}$ & $20 \%$ \\
\hline
\end{tabular}

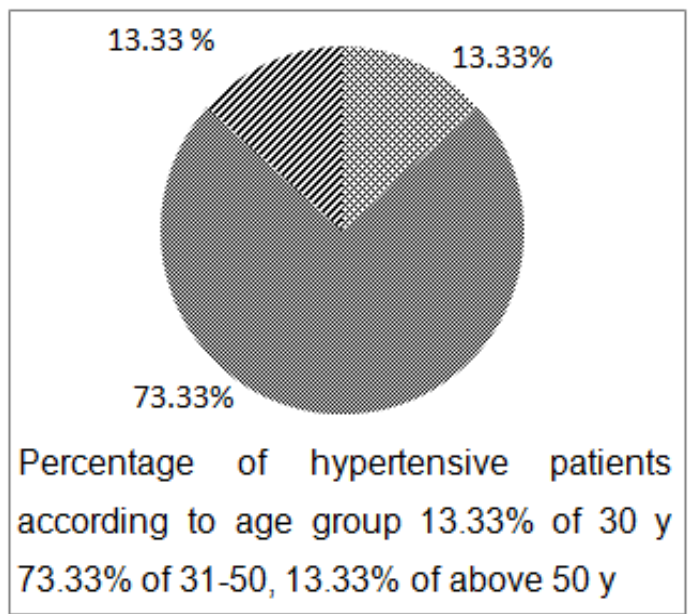

Fig. 1: Percentage of patient with age group

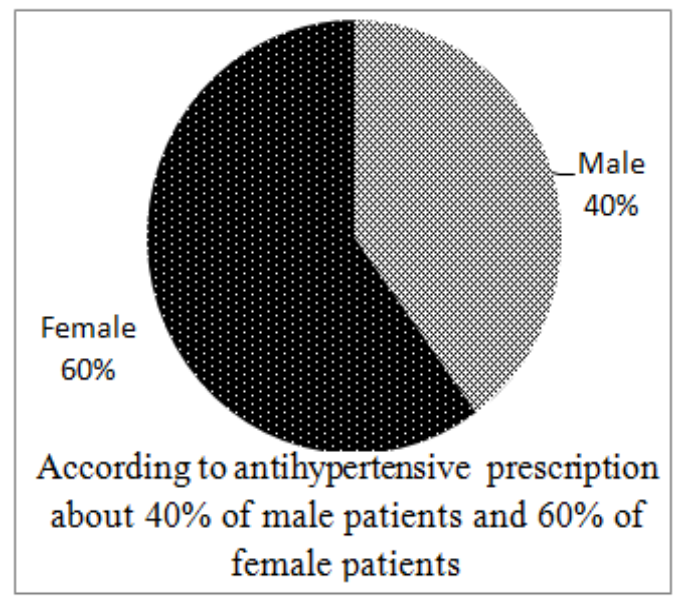

Fig. 2: Male-female percentage ratio

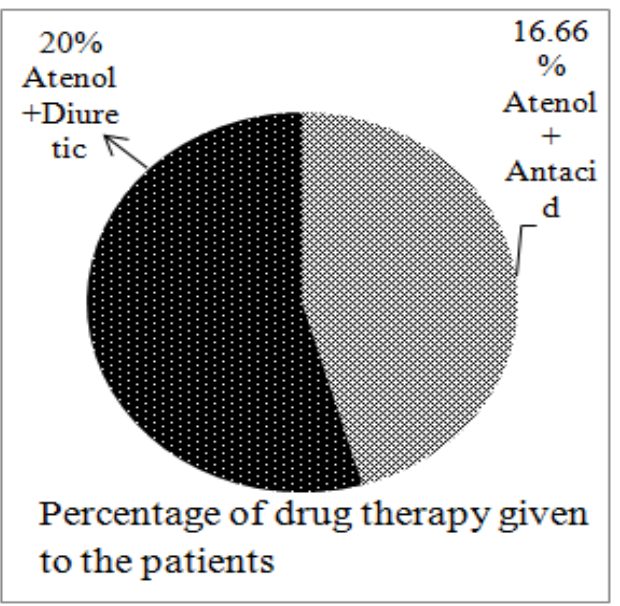

Fig. 3: Drug-drug interaction with $\beta$-Blockers

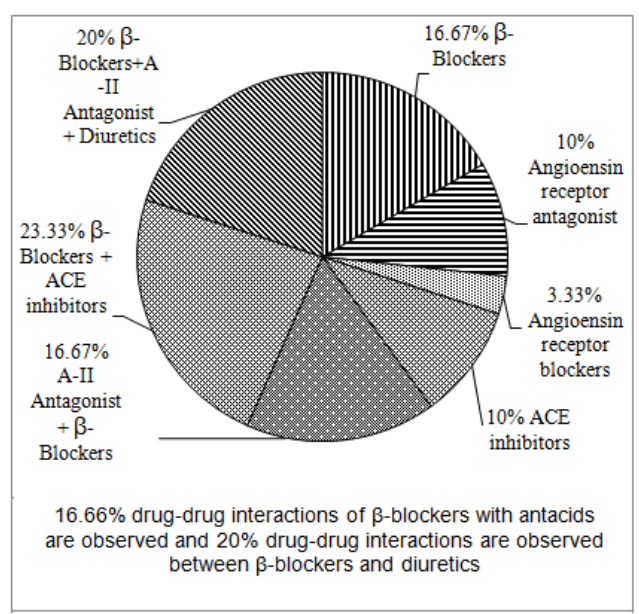

Fig. 4: Percentage of drug therapy given to the patients 
Table 5: Question answer in percentage

\begin{tabular}{lll}
\hline S. No. & Question & Percentage \\
\hline 1. & Physicians saying that antihypertensive activity of $\beta$ blocker within $1-3 \mathrm{w}$ & $100 \%$ \\
2. & Physicians saying that $\beta$ blocker is safe to give in asthmatic patient & $48 \%$ \\
3. & Physicians saying that $\beta$ blocker is safe to give in diabetic patient & $80 \%$ \\
4. & Physicians saying that $\beta 1$ selective blocker are more useful than non-selective $\beta$ blockers & $92 \%$ \\
5. & Physicians prescribing $\beta$ blockers with antacids & $84 \%$ \\
6. & Physicians saying that $\beta$ blockers are more useful in young age patients & $100 \%$ \\
7. & Physicians saying that $\beta$ blockers are safe in pregnancy \\
8. & Physicians prescribing CCB's and ACE inhibitors to old age patient & \\
9. & Physicians prescribing combination therapy of $\beta$ blockers+Diuretics \\
& \\
\hline
\end{tabular}

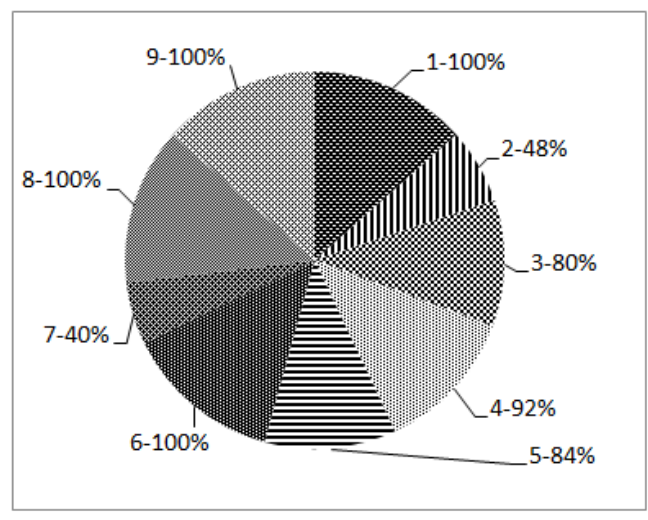

Fig. 5: Question no. and answer in percentage

\section{RESULTS AND DISCUSSION}

In our survey According to antihypertensive prescription about $40 \%$ of male and $60 \%$ of female patient are observe. All the physicians prefer to prescribe $\beta$ blockers in young age patients (table 1,2 ) In old age patient CCB's and ACE inhibitors are more commonly used than $\beta$ blockers. All the physicians are prescribing $\beta 1$ selective blockers than non-selective $\beta$ blockers. Only few physicians are prescribing $\beta$ blockers in physical conditions like asthma and pregnancy due to their side effects. $\beta$ blockers can be easily prescribed by physician in diabetic patient due to less side effects in this physical condition. There is about $16.66 \%$ drug-drug interactions of $\beta$-blockers with aluminum base antacids are observed [15]. 20\% drug-drug interactions are observed between $\beta$ blockers and diuretics. $\beta$ blockers+Diuretics are more commonly prescribed drug combination for hypertension (table 3,4 )

Antacids are more frequently used by physicians with $\beta$ blockers although there is drug-drug interaction among them. This is due to hypertensive patients usually suffer from acidity problems (table 5). But this combination causes decrease in absorption of $\beta 1$ selective blocker drug. This type of interactions is avoided by prolong medication of $\beta$ blockers and frequent monitoring B. P. of hypertensive patient by regular F/O. From the survey it is observed that $36.66 \%$ drug interaction observed among the all prescription. Therefore, it seems that although there is prolong medication and combination drug therapy to avoid drug-drug interaction of $\beta$ blockers but more number of drug-drug interactions are observed in case of $\beta$-blockers. Physicians are aware about drug-drug interaction of $\beta$-blockers but there are frequent cases of drug-drug interactions of $\beta$-blockers. Although there are more number of drug-drug interactions of $\beta$-blockers all over about $60 \%$ physicians are still prescribing $\beta$-blockers to treat hypertension. Therefore, it is needed to observe drug-drug interaction of $\beta$-blockers among various combinations to avoid it.

\section{ACKNOWLEDGEMENT}

Authors are grateful to Dr. Manohar J. Patil, Principal, Marathwada Mitra Mandal`s College of Pharmacy, Pune for providing the facility to conduct the study

\section{ABBREVIATIONS}

ACE: Angiotensin Converting Enzyme. FDC: Food Drug Combination. CCB: Calcium Chanel Blockers. LDL: low-density lipoprotein. HDL: High-density lipoprotein. References

\section{FUNDING}

Nil

\section{AUTHORS CONTRIBUTIONS}

All the authors have contributed equally.

\section{CONFLICT OF INTERESTS}

The authors declare no conflict of interest.

\section{REFERENCES}

1. Puoane T, Tsolekile L, Sanders D, Parker W. Chronic noncommunicable diseases. In: Barron P, Roma Reardon J. eds. South African Health Review. Durban: Health Systems Trust; 2008. p. 73-87.

2. Strong K, Mathers C, Leeder S, Beaglehole R. Preventing chronic diseases: how many lives can we save? Lancet 2005;366:1578-82.

3. Habib SH, Soma S. Burden of non-communicable disease: global overview. diabetes and metabolic syndrome. Clin Res Rev 2010;4:41-7.

4. Brown MJ, Haydock S. Pathoaetiology, epidemiology and diagnosis of hypertension. Drugs 2000;59 Suppl 2:1-12.

5. Guilbert JJ. The world health report 2002-reducing risks, promoting healthy life. Educ Health (Abingdon) 2003;16:230.

6. Kearney PM, Whelton M, Reynolds K, Muntner P, Whelton PK, He J. Global burden of hypertension: analysis of worldwide data. Lancet 2005;365:217-23.

7. Hypertension Study G. Prevalence, awareness, treatment and control of hypertension among the elderly in Bangladesh and India: a multicentre study. Bull World Health Organ 2001;79:490-500.

8. Nissinen A, Bothig S, Granroth H, Lopez AD. Hypertension in developing countries. World Health Stat Q 1988;41:141-54.

9. David Rodrigues, Drug-drug interaction. 2nd edition. Vol. 179. Stockley's Drug Interactions, Edited by Karen Baxter; 2009.

10. Hand book of Food drug interactions, Edited by Beverly J. McCabe Eric H. Frankel, Jonathan J. Wolfe CRC Press; 2003.

11. Pirmohamed M, James S, Meakin S, Green C, Scott AK, Walley $\mathrm{TJ}$, et al. Adverse drug reactions as cause of admissio to hospital: prospective analysis of 18820 patients. Br Med J 2004;329:15-9.

12. Royal S, Smeaton L, Avery AJ. Interventions in primary care to reduce medication related adverse events and hospital admissions: systematic review and meta-analysis. Qual Saf Health Care 2006;15:23-31.

13. Rupp MT, DeYoung M, Schondelmeyer SW. Prescribing problems and pharmacist interventions in community practice. Med Care 1992;30:926-40.

14. Leemans L, Veroeveren L, Bulens J, Hendrickx C, Keyenberg W, Niesten F, et al. Frequency and trends of intervention of prescriptions in flemish community pharmacies. Pharm World Sci 2003;25:65-9. 
15. Hong $\mathrm{CY}, \mathrm{Hu}$ SC, Lin SJ. Lack of influence of aluminum hydroxide on the bioavailability and beta-adrenoceptor blocking activity of propranolol. Int J Clin Pharmacol Ther Toxicol 1985;23:244-6. 